\title{
Downregulation of caffeoyl-CoA O-methyltransferase (CCOAOMT) by RNA interference leads to reduced lignin production in maize straw
}

\author{
Xiaoyu Li, Wenjuan Chen, Yang Zhao, Yan Xiang, Haiyang Jiang, Suwen Zhu and Beijiu Cheng \\ Key Laboratory of Crop Biology of Anhui Province, Anhui Agricultural University, Hefei, China.
}

\begin{abstract}
Lignin is a major cell wall component of vascular plants that provides mechanical strength and hydrophobicity to vascular vessels. However, the presence of lignin limits the effective use of crop straw in many agroindustrial processes. Here, we generated transgenic maize plants in which the expression of a lignin biosynthetic gene encoding CCOAOMT, a key enzyme involved in the lignin biosynthesis pathway was downregulated by RNA interference (RNAi). RNAi of CCOAOMT led to significantly downregulated expression of this gene in transgenic maize compared with WT plants. These transgenic plants exhibited a 22.4\% decrease in Klason lignin content and a $23.3 \%$ increase in cellulose content compared with WT plants, which may reflect compensatory regulation of lignin and cellulose deposition. We also measured the lignin monomer composition of the RNAi plants by GC-MS and determined that transgenic plants had a $57.08 \%$ higher S/G ratio than WT plants. In addition, histological staining of lignin with Wiesner reagent produced slightly more coloration in the xylem and sclerenchyma than WT plants. These results provide a foundation for breeding maize with low-lignin content and reveal novel insights about lignin regulation via genetic manipulation of CCOAOMT expression.
\end{abstract}

Keywords: CCoAOMT, lignin biosynthesis, lignin and cellulose content, Maize.

Received: April 26, 2013; Accepted: July 31, 2013.

\section{Introduction}

Lignin is a major component of plant cell walls and accounts for approximately $30 \%$ of the organic carbon in the biosphere (Boerjan et al., 2003). However, lignin in the plant cell walls hinders many agroindustrial processes, such as paper manufacturing and cellulosic biofuel production. Thus, many studies have focused on the repression or alteration of lignin biosynthesis to permit more efficient utilization of plant cell walls (Hu et al., 1999; Blee et al., 2001). Lignins from angiosperms are mainly polymerized from three cinnamyl alcohols (also called monolignols), including $p$-coumaryl, coniferyl and sinapyl alcohols, which form hydroxyphenyl $(\mathrm{H})$, guaiacyl $(\mathrm{G})$ and syringyl $(\mathrm{S})$ lignin, respectively. Accordingly, lignin biosynthesis in plants comprises two major steps, including monolignol biosynthesis and the subsequent crosslinking of lignin monomers to form different polymers (Boudet et al., 2003). Considerable effort has been directed towards understanding the mechanisms of monolignol biosynthesis.

The biochemical pathways of monolignol biosynthesis are highly conserved throughout vascular plants, and enzymes involved in these biosynthetic pathways have

Send correspondence to Beijiu Cheng. Key Laboratory of Crop Biology of Anhui Province, Anhui Agricultural University, 130 Changjiang Road, 230036 Hefei, China. E-mail: bjchengahau@163.com. been isolated and characterized. Recent studies have shown that at least 10 enzymes are required for monolignol biosynthesis, including phenylalanine ammonia-lyase (PAL), cinnamic acid 4-hydroxylase $(\mathrm{C} 4 \mathrm{H})$, 4-coumarate $\mathrm{CoA}$ ligase (4CL), p-coumarate 3-hydroxylase $(\mathrm{C} 3 \mathrm{H})$, p-hydroxycinnamoyl-CoA (HCT), caffeoyl-CoA O-methyltransferase (CCoAOMT), hydroxycinnamoyl-CoA reductase (CCR), cinnamyl alcohol dehydrogenase (CAD), ferulate 5-hydroxylase $(\mathrm{F} 5 \mathrm{H})$ and caffeic acid/5-hydroxyferulic acid O-methyltransferase (COMT) (Boudet et al., 2003). Lignin biosynthesis begins with the amino acid phenylalanine. PAL is one of the most intensively studied enzymes in plant secondary metabolism due to the key role that this enzyme plays in catalyzing the deamination reaction to produce cinnamic acid, which is then converted into $p$-coumaric acid by $\mathrm{C} 4 \mathrm{H}$. The downregulation of $P A L$ and $\mathrm{C} 4 \mathrm{H}$ gene expression in transgenic tobacco lead to a significant reduction in lignin content, which is consistent with the crucial roles of PAL and $\mathrm{C} 4 \mathrm{H}$ in phenylpropanoid biosynthesis (Bate et al., 1994; Elkind et al., 1990; Sewalt, et al., 1997). In addition, studies have also shown that PAL is mainly responsible for the biosynthesis of G-lignin, while the downregulation of $P A L$ expression in plants mainly leads to a reduction in the $\mathrm{G}$ units of lignin, whereas the downregulation $C 4 H$ expression mainly leads to a reduction in $\mathrm{S}$ units of lignin. In addition, many studies have shown that lignin content can by altered by modifying the 
expression of other key enzymes in the lignin biosynthesis pathway. For example, increasing evidence suggested that CCOAOMT is involved in a parallel pathway for lignin monomer formation (Ye et al., 1994; Zhong et al., 1998). The downregulation of CCOAOMT results in a reduction in lignin production, along with an increase in the $\mathrm{S} / \mathrm{G}$ ratio due to a reduction in G units (Ye et al., 1994; Guo et al., 2001; Pincon et al., 2001; Boerjan et al., 2003). Studies from transgenic plants have shown that the downregulation of COMT expression leads the reduced production of $\mathrm{S}$ units, which suggests that COMT is mainly responsible for the biosynthesis of S monomers (Tsai et al., 1998; Lapierre et al., 1999; Doorsselaere et al., 2003).

Maize (Zea mays L.) straw is one of the most important leading forage crops. However, maize straw contains considerable amounts of lignin, which seriously affects the digestion and nutrient absorption of maize straw by livestock. Moreover, high lignin content in plant cell walls has a negative impact on forage quality (Marita et al., 2003). As mentioned above, many studies have examined the effect of enzymes at key positions in the monolignol biosynthesis pathway such as CCoAOMT and COMT. In this study, a $229 \mathrm{bp}$ fragment corresponding to the fifth exon of maize CCOAOMT was generated by PCR amplification to construct RNA interference (RNAi) expression vector, which was transferred into maize by Agrobacterium-mediated transformation. The results showed that the repressed expression of CCOAOMT in maize largely reduces the lignin content of maize straw and significantly increases the $\mathrm{S} / \mathrm{G}$ ratio and cellulose content. The results of this study reveal new details about the effects of the downregulation of CCOAOMT on lignin regulation and provide a basis for further studies aimed at breeding plants with low lignin content.

\section{Materials and Methods}

\section{Constructs and maize transformation}

The maize inbred line B73 was cultivated in a greenhouse at $28{ }^{\circ} \mathrm{C}$ with a $14: 10 \mathrm{~h} \mathrm{light/dark}$ photoperiod. Genomic DNA was extracted from the leaves of B73 using the hexadecyl trimethylammonium bromide (CTAB) method. This DNA was used in the amplification of the $229 \mathrm{bp}$ fragment corresponding to the fifth exon of maize CCOAOMT (EU952463). To construct the RNAi expression vector, gene-specific primers 5'-TAAGGATCCAGAAGAACCACGGGTCGTTCGAC -3' (forward, BamHI site underlined) and 5'-TAAGTCGACTCGTCGGCGGCGAGCGCCTTG-3' (reverse, SalI site underlined) were used to amplify the $229 \mathrm{bp}$ forward fragment. The products were cloned into the pMD18-T simple vector (TaKaRa, Japan), sequenced and then subcloned into the pUCCRNAi vector. The same fragment was inserted in the antisense orientation of the pUCCRNAi+1F vector digested with BglII and $X h o \mathrm{I}$ (compatible restriction endonucleases of BamHI and SalI) to con- struct the pUCCRNAi $+2 \mathrm{~F}$ vector. Subsequently, the $2 \mathrm{~F}$ fragment (sense orientation fragment, antisense orientation fragment and an intron) was isolated from pUCCRNAi $+2 \mathrm{~F}$ vector and inserted into pCAMBIA1301 (Bar) vector under the control of a cauliflower mosaic virus (CaMV) 35S promoter. The construct was introduced into Agrobacterium tumefaciens strain Agl0 by the freeze-thaw method and then transformed into maize inbred line zheng 58 by a previously described method ( $\mathrm{Li}$, et al., 2008) with some modifications.

\section{Polymerase chain reaction (PCR) amplification and Southern blotting}

Phosphinothricin-resistant plants were confirmed by amplifying the $35 \mathrm{~S}$ promoter from DNA isolated from these plants using the following primers: 5'-CCACAGATGGTTAGAGAGG-3' (forward) and 5'-GTCTTGCGAAGGATAGTGG-3' (reverse). For Southern blotting analysis, the DNA of PCR-positive transgenic plants was digested overnight with EcoRI, separated by electrophoresis on a $0.8 \%$ agarose gel and transferred onto a Hybond- $\mathrm{N}^{+}$nylon membrane (Amersham Pharmacia, UK). Southern blotting was performed with a digoxigenin (DIG)-labeled $35 \mathrm{~S}$ promoter probe according to the manufacturer's instructions (Roche, Germany).

\section{Expression of CCOAOMT in transgenic plants}

Total RNA from untreated maize leaves was extracted with Trizol reagent (Invitrogen, USA) and treated with DNase I (Invitrogen, USA) for 20 min to remove possible contaminating genomic DNA. The first-strand cDNA was synthesized from $1 \mu \mathrm{g}$ of total RNA using M-MLV reverse transcriptase according to the manufacturer's instructions (Invitrogen, USA). Semi-quantitative RT-PCR (semiRT-PCR) was performed to detect the expression levels of maize CCOAOMT in different transgenic lines using the following thermal profile: $94{ }^{\circ} \mathrm{C}$ for $5 \mathrm{~min}$ followed by 34 cycles of $94{ }^{\circ} \mathrm{C}$ for $30 \mathrm{~s}, 58{ }^{\circ} \mathrm{C}$ for $30 \mathrm{~s}$, and $72{ }^{\circ} \mathrm{C}$ for $30 \mathrm{~s}$, with a final extension at $72{ }^{\circ} \mathrm{C}$ for $10 \mathrm{~min}$. The maize Actinl gene was amplified as an internal control using primers 5'-GTTGGGCGTCCTCGTCA-3' (forward) and 5'-TGGGTCATCTTCTCCCTGTT-3' (reverse).

\section{Determination of Klason lignin, cellulose and hemicelluloses contents in maize straw}

The lignin content was analyzed as acid-insoluble Klason lignin according to the Chinese National Standards GB/T 747-2003. Cellulose content was determined by the nitric acid-ethanol method (Shi and He, 2003). Hemicelluloses content was detected as described previously (Xiao et al., 2001).

\section{Determination of Klason lignin monomer composition}

Stems of transgenic and WT plants were dried and treated for thioacidolysis followed by gas chromatography 
mass spectrometry (GC-MS), to measure the monolignol composition. GC-MS analysis was performed on a Thermo Scientific iCAP 6300 device as described previously, with some modification (González-Vila et al., 1999; Mullen and Boateng, 2010).

\section{Histological staining of lignin}

Lignin histological staining was performed using Wiesner reagent (Pomar et al., 2004). Stems of transgenic and WT plants were fixed in FAA solution, dehydrated through an alcohol series, embedded in paraffin and cut with a cryostat CM1900 microtome (Leica, Germany) into $40-\mu \mathrm{m}$-thick sections. Cross-sections of maize stems were incubated in a $2.5 \%(\mathrm{w} / \mathrm{v})$ solution of phloroglucinol for 5 min, treated with $20 \% \mathrm{HCl}$ for 5 min and observed under an Olympus FV1000 confocal microscope (Olympus, Japan).

\section{Results}

\section{Expression level of maize CCoAOMT gene ( $Z m C o A)$ in RNAi transgenic plants}

A $229 \mathrm{bp}$ fragment was generated from the genomic DNA of maize inbred line B73 by PCR-amplification. Sequence alignment indicated that the $229 \mathrm{bp}$ fragment shared $100 \%$ identity with the fifth exon of the CCOAOMT coding sequence (GRMZM2G127948_T01) from 485-713 bp (Supplementary material Figure S1A). This fragment was used to construct the RNA interference fragment (Figure S1B). Through Agrobacterium tumefaciens mediated transformation, a total of six PCR-positive plants were obtained (Figure S2A), and two single-copy transgenic plants, designated L1 and L2 (Figure S2B), were chosen for further experiments by Southern blotting. Both transgenic plants exhibited similar phenotypes with a characteristic of slightly delayed growth compared with WT plants (Figure 1).

To detect the expression level of $\mathrm{ZmCoA}$ in transgenic maize plants, total RNAs were extracted from L1 and L2 transgenic lines of $\mathrm{T}_{1}$ plants. Three L1 (L1-1, L1-2 and L1-3) and two L2 lines (L2-1 and L2-2) were chosen randomly and subjected to semiRT-PCR analysis. The results showed that the expression of $\mathrm{ZmCoA}$ in transgenic plants was down-regulated in the transgenic plants compared with WT plants (Figure 2), suggested that the expression of $\mathrm{ZmCoA}$ in transgenic plants was significantly repressed due to the presence of the RNAi expression vector.

\section{Effects of downregulated CCOAOMT expression on lignin, cellulose and hemicelluloses contents}

To examine the effects of downregulation of CCoAOMT in maize, the Klason lignin content was measured in WT and transgenic plants. Compared with WT plants, the Klason lignin content was significantly reduced in transgenic plants. The average Klason lignin content of the transgenic plants was reduced to $10.35 \%$, while the WT

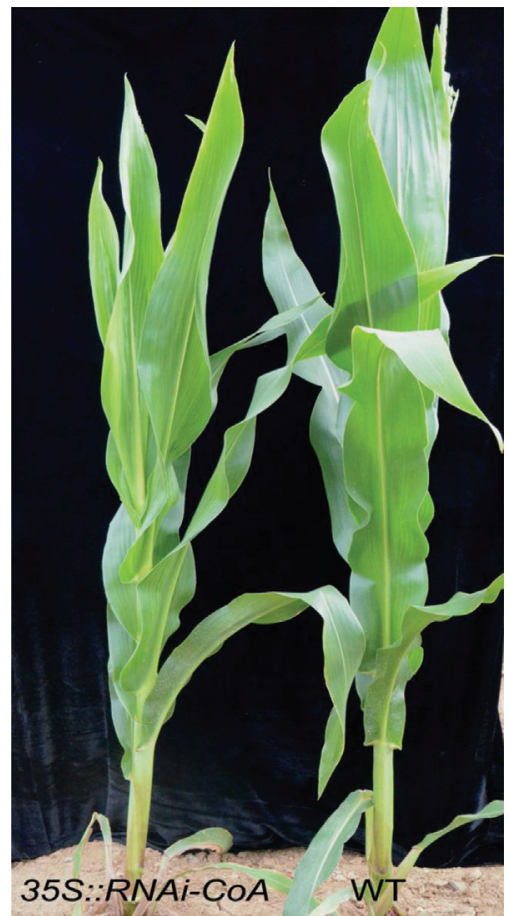

Figure 1 - Phenotype of RNAi CCOAOMT transgenic plants and WT plants grown in soil.

plants contained $13.34 \%$ Klason lignin (Figure 3A). The largest reductions in Klason lignin content was detected in the L1-1 line $(9.94 \%)$.

The cellulose contents were also compared between WT and transgenic plants. In contrast to the Klason lignin content, the cellulose content of transgenic plants was significantly higher than that of WT plants. The cellulose content of transgenic plants ranged from $45.32 \%$ to $49.73 \%$, while the WT plants contained only $38.4 \%$ cellulose (Figure 3B). Interestingly, the transgenic line L1-1 had the highest cellulose content among the transgenic plants, suggesting that cellulose biosynthesis is regulated by the down-regulation of $\mathrm{ZmCoA}$ in transgenic plants. The content of hemicelluloses was also determined in this study. As shown in Figure 3C, there were no significant differences between transgenic and WT plants, although some transgenic plants exhibited slightly increased levels. Indeed, the down-regulation of CCOAOMT in maize led to a $22.4 \%$ decrease in Klason lignin content and a $23.3 \%$ increase in cel-

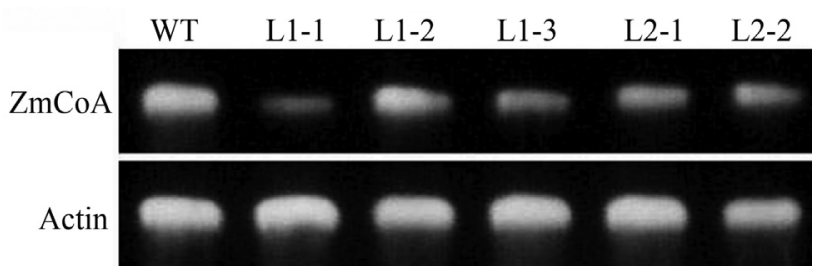

Figure 2 - Expression levels of CCOAOMT in WT plants and independent transgenic lines. The maize Actinl gene was used as internal control for PCR. 

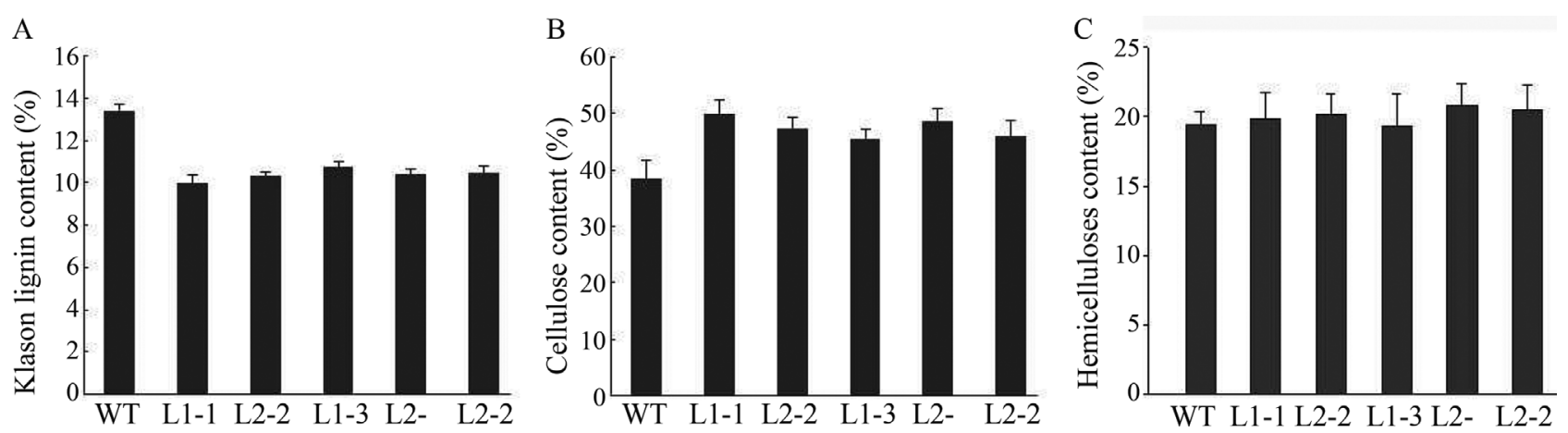

Figure 3 - Klason lignin content (A), cellulose content (B) and hemicelluloses content (C) in RNAi CCoAOMT transgenic plants and WT plants. Data are means \pm SD of three replicates.

lulose content $v s$. the WT plants. Based on these results, we conclude that lignin and cellulose, important cell wall components in plants, may be regulated in a compensatory fashion, which is consistent with previous reports ( $\mathrm{Hu}$ et al., 1999).

\section{Downregulation of $C C O A O M T$ results in altered of $S / G$ ratios}

Many studies of other species have shown that the down-regulation of CCOAOMT can lead to a reduction in lignin content and an increase in the $\mathrm{S} / \mathrm{G}$ ratio. Thioacidolysis is the most efficient method for degrading lignin polymers to reveal the lignin monomer composition (Lapierre et al., 1995). Thus, in this study, maize stems of transgenic and WT plants were treated with thioacidolysis, followed by GC-MS, to measure the monolignol compositions of syringyl (S) and guaiacyl (G). As shown in Figure 4 , the $\mathrm{S} / \mathrm{G}$ ratio of the transgenic plants was 0.999 , while the $\mathrm{S} / \mathrm{G}$ ratio of WT plants was only 0.636 . Therefore, the transgenic plants had a $57.08 \%$ higher $\mathrm{S} / \mathrm{G}$ ratio than WT plants, which is consistent with previous reports.

\section{Effects of downregulation CCOAOMT on lignin deposition}

Lignin content is reflected by the intensity of phloroglucinol staining in the cell walls, while non-lignified cells are not clearly visible by this method. To examine lignin deposition in maize straw, cross-sections of stems of transgenic and WT plant were strained with the lignin-staining dye phloroglucinol-HCl (Wiesner reagent) to reveal lignin deposition. As shown in Figure 5, after Wiesner staining, lignin was barely visible in the transgenic plants, suggesting that down-regulation of $C C O A O M T$ in maize led to a reduction in lignin staining (Figure 5B). By contrast, staining with Wiesner reagent produced a significant brown coloration in the xylem and sclerenchyma of WT plants (Figure $5 \mathrm{~A}$ ). These results suggest that down-regulation of CCOAOMT resulted in a dramatic reduction of lignin content in maize straw.

\section{Discussion}

Plants with low lignin content can be obtained through breeding and selection, or by purposely altering lignin content through genetic engineering. Since lignin biosynthesis pathways are highly conserved in most plant species (Boerjan et al., 2003; Umezawa, 2010), genetic engineering can be employed to directly manipulate the target genes involved in the lignin biosynthesis pathway by down-regulating the expression of these genes, or by manipulating transcription factors that regulate the expression of key lignin synthesis gene(s) (Sánchez et al., 2005; Zhou et al., 2009; Xu et al., 2011;). To date, at least ten genes encoding the key enzymes in the lignin biosynthesis pathway have been isolated and characterized. Various enzymes in the lignin biosynthesis pathway have been shown to play important roles in regulating lignin content and quality. Amongst the genes encoding these enzymes, CCOAOMT was discovered only recently, and has mainly been studied in tobacco, poplar and Medicago (Martz et al., 1998; Meyermans et al., 2000; Guo et al., 2001). Despite the importance of maize for forage and industrial materials, few studies have focused on the functional characterization of lignin synthesis-related genes in maize. In this study, a 229 bp fragment of maize CCOAOMT corresponding to the fifth exon of this gene was used to construct an RNAi vector, which was then transferred into maize. The results of this study confirmed many features of CCOAOMT that were previously reported, but also revealed some new aspects of this gene that differ from those observed in other species.

In transgenic poplar and alfalfa with repressed CCOAOMT activity, down-regulation of CCOAOMT leads to a general reduction in Klason lignin content but an increase in the S/G ratio (Meyermans et al., 2000; Zhong et al., 2000; Guo et al., 2001). In addition, transgenic studies have indicated that the increase in the $\mathrm{S} / \mathrm{G}$ ratio results mainly from a decrease in the amount of $G$ units, with no reduction in S lignin. Our results showed that down-regulation of CCOAOMT in maize can largely reduce the Klason lignin content and significantly increase the $\mathrm{S} / \mathrm{G}$ ratio, 

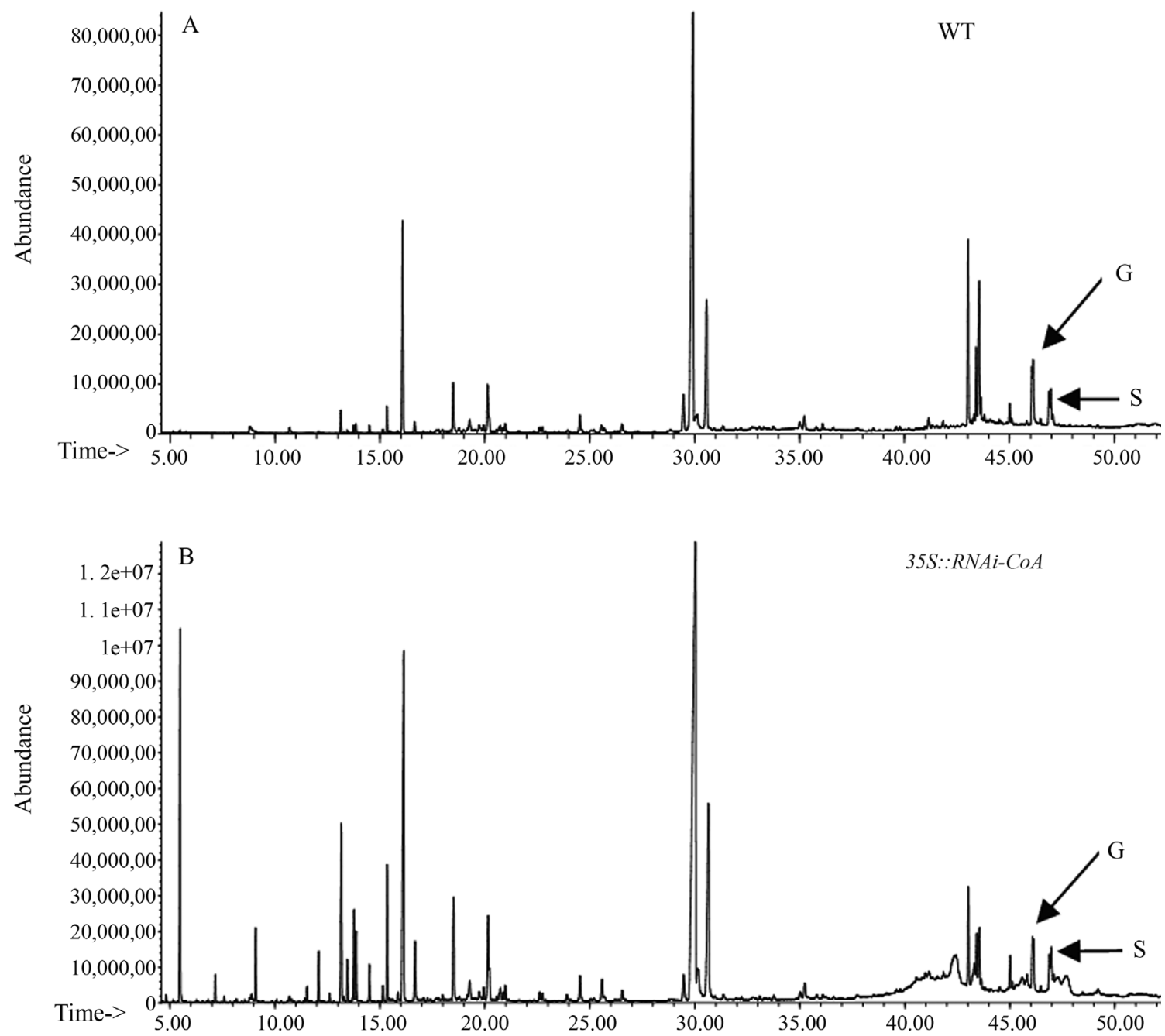

Figure 4 - GC-MS chromatogram of syringyl (S) and guaiacyl (G) units isolated from WT (A) and CCoAOMT downregulated transgenic plants (B).

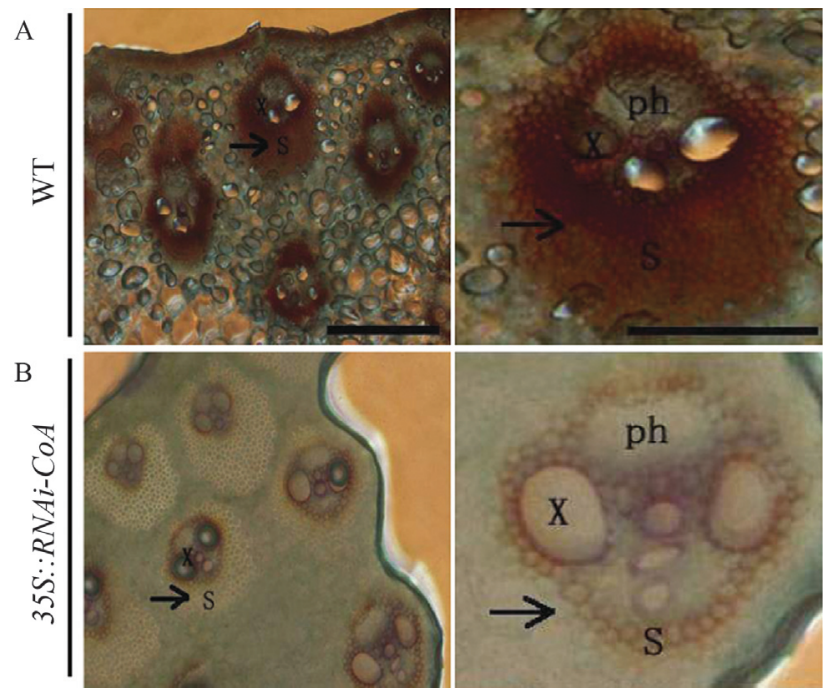

Figure 5 - Histological staining for lignin deposition in stem crosssections of WT (A) and RNAi CCOAOMT transgenic maize plants using Wiesner reagent (B). $X$ xylem, $S$ sclerenchyma, $p h$ phloem. which are consistent with the previous studies. Meyermans et al. (2000) showed that introducing the antisense of CCOAOMT into transgenic poplar resulted in an $11 \%$ increase in the $\mathrm{S} / \mathrm{G}$ ratio. By contrast, our results showed that the $\mathrm{S} / \mathrm{G}$ ratio in plants with downregulated CCOAOMT expression was $57.08 \%$ higher than that of WT plant, possibly due to the different plant species or methods used to repress gene expression in these two studies. More interestingly, transgenic plants showed a concomitant increase in cellulose content in the lignin-reduced transgenic plants, suggesting that lignin and cellulose deposition may be regulated in a compensatory fashion in maize, which may contribute to metabolic flexibility and a growth advantage to help sustain mechanical strength in lignin-deficient straw. However, the mechanism by which this compensatory phenomenon in lignin and cellulose deposition occurs is still unknown.

To obtain plants with reduced lignin, studies should focus not only on lowing lignin content and composition, but also on the selection of transgenic plants with normal development. Many studies have focused on altering the 
expression of various enzymes in the lignin biosynthesis pathway, some of which have had important effects on plant growth and development. For example, downregulation of $4 C L$ in transgenic aspen leads to reduced lignin content, but also to the production of plants with enhanced growth phenotypes such as thicker stems, longer internodes, and larger leaves than control plants (Hu et al., 1999). On the contrary, down-regulation of $C C R$ in Leucaena leucocephala produced plants with significant changes in phenotypes, such as stunted growth and development, wrinkled leaves, and delayed senescence, with a $24.7 \%$ reduction of Klason lignin $v s$. WT plants (Prashant et al., 2011). In the current study, transgenic maize plants with downregulated CCOAOMT expression exhibited significant reductions in Klason lignin, but displayed a normal phenotype compared with control plants, besides a slightly delayed growth, suggesting that $C C O A O M T$ is an effective and ideal target gene for the regulation of the lignin biosynthesis pathway. However, there is an inherent relationship between lignin content and plant lodging resistance. Although our results show that plants with down-regulated CCOAOMT expression had almost normal phenotypes, except the slightly delayed growth, we did not adequately address the effect of reduced lignin content on lodging resistance in these lines, due to the small number of independent transgenic lines obtained in this study. Thus, more transgenic lines will be required to examine the effects of reduced lignin content on lodging resistance in maize in a future study. In addition, lignin deposition is influenced by abiotic and biotic stresses (Halpin, 2004; Boudet, 2007), it will be interesting to compare the lignin content of CCOAOMT down-regulated plants under field and greenhouse conditions.

\section{Acknowledgments}

This work was supported by grants from the National Natural Science Foundation of China (31071423). We would like to thank the members of the Key Laboratory of Crop Biology of Anhui Province for their assistance in this study.

\section{References}

Bate NJ, Orr J, Ni W, Meromi A, Nadler-Hassar T, Doerner PW, Dixon RA, Lamb CJ and Elkind Y (1994) Quantitative relationship between phenylalanine ammonia-lyase levels and phenylpropanoid accumulation in transgenic tobacco identifies a rate-determining step in natural product synthesis. Proc Natl Acad Sci USA 91:7608-7612.

Blee K, Choi JW, O'Connell AP, Jupe SC, Schuch W, Lewis N and Bolwell GP (2001) Antisense and sense expression of cDNA coding for CYP73A15, a class II cinnamate 4-hydroxylase, leads to a delayed and reduced production of lignin in tobacco. Phytochemistry 57:1159-1166.

Boerjan W, Ralph J and Baucher M (2003) Lignin biosynthesis. Annu Rev Plant Biol 54:519-546.
Boudet AM (2007) Evolution and current status of research in phenolic compounds. Phytochemistry 68:2722-2735.

Boudet AM, Kajita S, Grima-Pettenati J and Goffner D (2003) Lignins and lignocellulosics: A better control of synthesis for new and improved uses. Trends Plant Sci 8:576-581.

Doorsselaere J, Baucher M, Chognot E, Chabbert B, Tollier MT, Petit-Conil M, Leplé JC, Pilate G, Cornu D and Monties B (2003) A novel lignin in poplar trees with a reduced caffeic acid/5 hydroxyferulic acid $\mathrm{O}$ methyltransferase activity. Plant J 8:855-864.

Elkind Y, Edwards R, Mavandad M, Hedrick SA, Ribak O, Dixon RA and Lamb CJ (1990) Abnormal plant development and down-regulation of phenylpropanoid biosynthesis in transgenic tobacco containing a heterologous phenylalanine ammonia-lyase gene. Proc Natl Acad Sci USA 87:9057-9061.

González-Vila FJ, Almendros G, Del Río J, Martin F, Gutiérrez A and Romero J (1999) Ease of delignification assessment of wood from different Eucalyptus species by pyrolysis (TMAH)-GC/MS and CP/MAS 13C-NMR spectrometry. J Anal Appl Pyrol 49:295-305.

Guo D, Chen F, Inoue K, Blount JW and Dixon RA (2001) Downregulation of caffeic acid 3-O-methyltransferase and caffeoyl CoA 3-O-methyltransferase in transgenic alfalfa: impacts on lignin structure and implications for the biosynthesis of $\mathrm{G}$ and $\mathrm{S}$ lignin. Plant Cell 13:73-88.

Halpin C (2004) Re-designing lignin for industry and agriculture. Biotechnol Genet Eng Rev 21:229-245.

Hu WJ, Harding SA, Lung J, Popko JL, Ralph J, Stokke DD, Tsai CJ and Chiang VL (1999) Repression of lignin biosynthesis promotes cellulose accumulation and growth in transgenic trees. Nat Biotechnol 17:808-812.

Lapierre C, Pollet B, Petit-Conil M, Toval G, Romero J, Pilate G, Leple JC, Boerjan W, Ferret VV, De Nadai V, et al. (1999) Structural alterations of lignins in transgenic poplars with depressed cinnamyl alcohol dehydrogenase or caffeic acid O-methyltransferase activity have an opposite impact on the efficiency of industrial kraft pulping. Plant Physiol 119:153-164.

Lapierre C, Pollet B and Rolando C (1995) New insights into the molecular architecture of hardwood lignins by chemical degradative methods. Res Chem Intermediat 21:397-412.

Li B, Wei A, Song C, Li N and Zhang J (2008) Heterologous expression of the TsVP gene improves the drought resistance of maize. Plant Biotechnol J 6:146-159.

Marita JM, Ralph J, Hatfield RD, Guo D, Chen F and Dixon RA (2003) Structural and compositional modifications in lignin of transgenic alfalfa down-regulated in caffeic acid 3-Omethyltransferase and caffeoyl coenzyme A 3-O-methyltransferase. Phytochemistry 62:53-65.

Martz F, Maury S, Pinçon G and Legrand M (1998) cDNA cloning, substrate specificity and expression study of tobacco caffeoyl-CoA 3-O-methyltransferase, a lignin biosynthetic enzyme. Plant Mol Biol 36:427-437.

Meyermans H, Morreel K, Lapierre C, Pollet B, De Bruyn A, Busson R, Herdewijn P, Devreese B, Van Beeumen J and Marita JM (2000) Modifications in lignin and accumulation of phenolic glucosides in poplar xylem upon downregulation of caffeoyl-coenzyme A O-methyltransferase, an enzyme involved in lignin biosynthesis. J Biol Chem 275:36899-36909. 
Mullen CA and Boateng AA (2010) Catalytic pyrolysis-GC/MS of lignin from several sources. Fuel Process Technol 91:1446-1458.

Pincon G, Maury S, Hoffmann L, Geoffroy P, Lapierre C, Pollet B and Legrand M (2001) Repression of O-methyltransferase genes in transgenic tobacco affects lignin synthesis and plant growth. Phytochemistry 57:1167-1176.

Pomar F, Novo M, Bernal MA, Merino F and Barcelo AR (2004) Changes in stem lignins (monomer composition and crosslinking) and peroxidase are related with the maintenance of leaf photosynthetic integrity during Verticillium wilt in Capsicum annuum. New Phytol 163:111-123.

Prashant S, Srilakshmi Sunita M, Pramod S, Gupta RK, Anil Kumar S, Rao Karumanchi S, Rawal SK and Kavi Kishor PB (2011) Down-regulation of Leucaena leucocephala cinnamoyl CoA reductase (LlCCR) gene induces significant changes in phenotype, soluble phenolic pools and lignin in transgenic tobacco. Plant Cell Rep 30:2215-2231.

Sánchez JP, Ullman C, Moore M, Choo Y and Chua NH (2005) Regulation of Arabidopsis thaliana 4 coumarate: coenzyme A ligase 1 expression by artificial zinc finger chimeras. Plant Biotechnol J 4:103-114.

Sewalt V, Ni W, Blount JW, Jung HG, Masoud SA, Howles PA, Lamb C and Dixon RA (1997) Reduced lignin content and altered lignin composition in transgenic tobacco downregulated in expression of L-phenylalanine ammonia-lyase or Cinnamate 4-hydroxylase. Plant Physiol 115:41-50.

Shi S and He F (2003) Analysis and Detection of Pulping and Papermaking. Chinese Light Industry Press, Beijing.

Tsai CJ, Popko JL, Mielke MR, Hu WJ, Podila GK and Chiang VL (1998) Suppression of O-methyltransferase gene by homologous sense transgene in quaking aspen causes redbrown wood phenotypes. Plant Physiol 117:101-112.

Umezawa T (2010) The cinnamate/monolignol pathway. Phytochem Rev 9:1-17.
Xiao B, Sun X and Sun R (2001) Chemical, structural, and thermal characterizations of alkali-soluble lignins and hemicelluloses, and cellulose from maize stems, rye straw, and rice straw. Polymer Degrad Stabil 74:307-319.

Xu B, Escamilla-Treviño LL, Sathitsuksanoh N, Shen Z, Shen H, Percival Zhang YH, Dixon RA and Zhao B (2011) Silencing of 4-coumarate: coenzyme A ligase in switchgrass leads to reduced lignin content and improved fermentable sugar yields for biofuel production. New Phytol 192:611-625.

Ye ZH, Kneusel RE, Matern U and Varner JE (1994) An alternative methylation pathway in lignin biosynthesis in Zinnia. Plant Cell 6:1427-1439.

Zhong R, Iii WH, Negrel J and Ye ZH (1998) Dual methylation pathways in lignin biosynthesis. Plant Cell 10:2033-2046.

Zhong R, Morrison WH, 3rd, Himmelsbach DS, Poole FL, 2nd, and Ye ZH (2000) Essential role of caffeoyl coenzyme A O-methyltransferase in lignin biosynthesis in woody poplar plants. Plant Physiol 124:563-578.

Zhou J, Lee C, Zhong R and Ye ZH (2009) MYB58 and MYB63 are transcriptional activators of the lignin biosynthetic pathway during secondary cell wall formation in Arabidopsis. Plant Cell 21:248-266.

\section{Supplementary Material}

The following online material is available for this article:

Figure S1 - Molecular characterization of CCOAOMT downregulated transgenic plants.

Figure S2 - PCR confirmation of CCOAOMT downregulated transgenic lines by amplifying the $35 \mathrm{~S}$ promoter.

This material is available as part of the online article from http://www.scielo.br/gmb.

Associate Editor: Márcio de Castro Silva-Filho

License information: This is an open-access article distributed under the terms of the Creative Commons Attribution License, which permits unrestricted use, distribution, and reproduction in any medium, provided the original work is properly cited. 


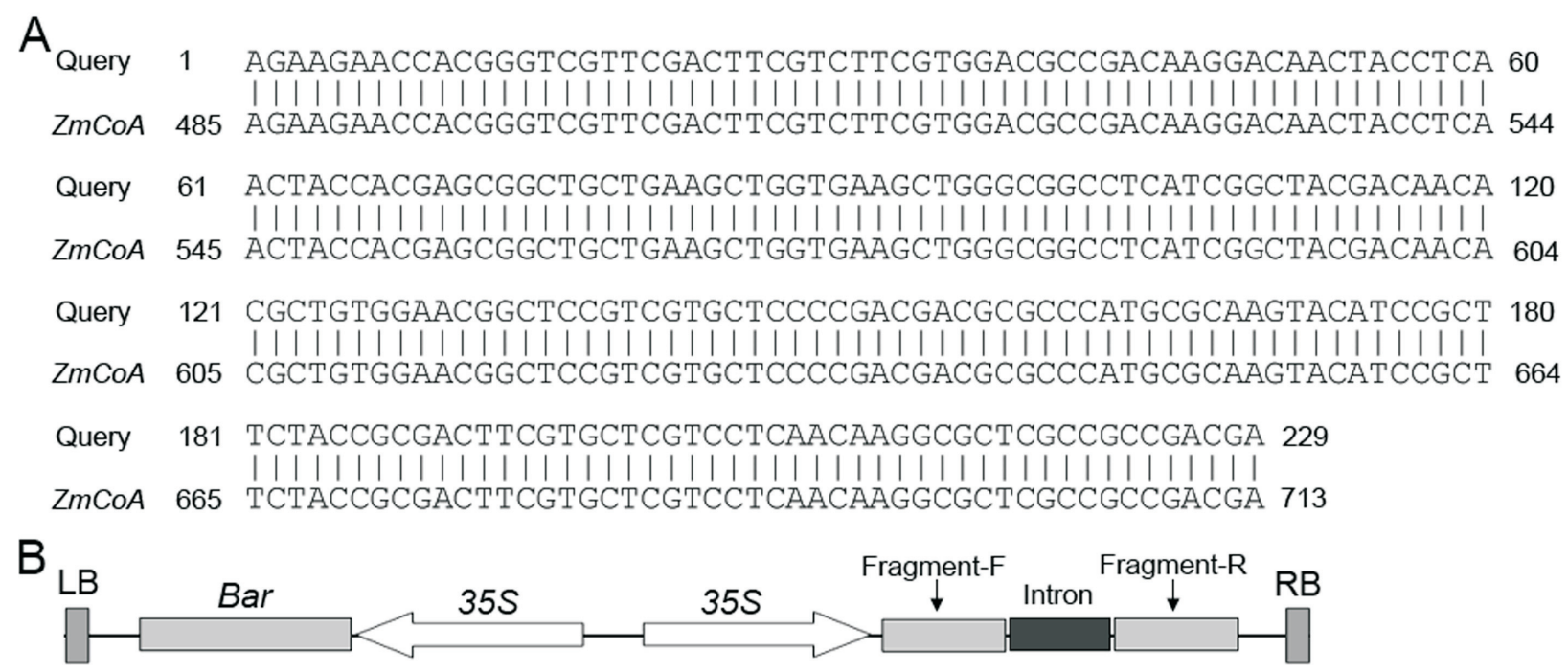

Figure S1 - Molecular characterization of $C$ COAOMT down-regulated transgenic plants. 


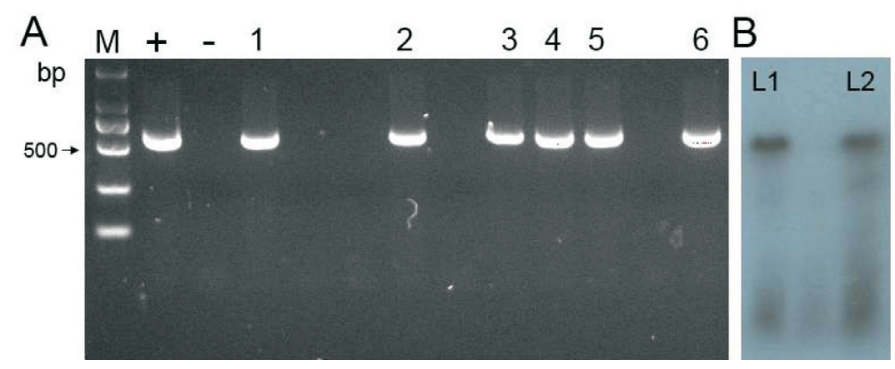

Figure S2 - PCR confirmation of CCOAOMT downregulated transgenic lines by amplifying the 35S promoter. 